\title{
Combined PRK and PTK in myopic patients with recurrent corneal erosion
}

\author{
I Kremer, M Blumenthal
}

\begin{abstract}
Aim-To study the results of combined photorefractive keratectomy (PRK) and phototherapeutic keratectomy (PTK) in myopic patients with recalcitrant recurrent corneal erosion.

Methods-PRK was performed in 16 eyes with the Visx 20/20 excimer laser at a central $6.0 \mathrm{~mm}$ zone, following total epithelial scraping. Subsequently, confluent $3.0 \mathrm{~mm}$ zones of PTK were ablated at a depth of $6.0 \mu \mathrm{m}$, surrounding the zone of PRK. The follow up period ranged from 26 to 42 months.

Results-Complete alleviation of symptoms was demonstrated and there was no recurrence of corneal erosion. Visual acuity (VA) improved slowly following treatment, with a final uncorrected VA ranging between $6 / 9$ and 6/12. A final myopic spherical equivalent $\leqslant-1.0 \mathrm{D}$ was found in 14 out of 16 eyes.

Conclusions-A combination of PRK and PTK is effective in the alleviation of symptoms and prevention of recurrences of corneal erosion. It is suggested that recalcitrant recurrent corneal erosion is a diffuse disease, although it often manifests as a local problem, and therefore extensive excimer laser ablation is required to prevent recurrence and to alleviate symptoms completely.

(Br f Ophthalmol 1997;81:551-554)
\end{abstract}

Recurrent corneal erosion (RCE) is a disorder of the epithelial basement membrane which is frequently associated with a previous history of shallow corneal injury and, less frequently, with epithelial basement dystrophy (EBMD). ${ }^{1-5}$ Abnormal epithelial basement membrane or abnormal deposition of epithelial basement membrane are believed to play an important role in the pathogenesis of this disease..$^{3-5}$ The importance of anchoring systems in maintaining epithelial adhesion has long been established ${ }^{6}$ and defective anchoring systems have been incriminated in recurrent corneal erosion and other anterior basement membrane disorders. ${ }^{7-13}$

Patients with EBMD or trauma related focal epithelial basement membrane abnormality were found to be more likely to present with chronic recurrent symptoms than trauma related cases with no anterior basement membrane abnormality on slit-lamp examination. ${ }^{14}$

In the majority of cases, the acute episode of corneal epithelial erosion is managed success- fully by patching and prophylactic ointment at night to prevent further episodes. ${ }^{314}$ In a minority of cases, these measures are insufficient and recurrent painful episodes occur. ${ }^{314}$ Alternative treatments include therapeutic contact lens wear, ${ }^{515}$ needle anterior stromal puncture, ${ }^{16}{ }^{17}$ scraping or superficial epithelial keratectomy, ${ }^{18}{ }^{19} \mathrm{Nd}$ :YAG laser anterior stromal puncture, ${ }^{20}{ }^{21}$ microdiathermy, ${ }^{22}$ and excimer laser phototherapeutic keratectomy. ${ }^{23} 24$ The relative efficacy of these therapies has been difficult to assess because of the varied indications applied to their use, and their mechanism of action has not yet been clearly defined.

We present our follow up results of pancorneal excimer laser photoablation, including the combination of photorefractive keratectomy (PRK) and phototherapeutic keratectomy (PTK), for myopic patients with recalcitrant recurrent erosion syndrome, unresponsive to epithelial scraping and subsequent patching.

\section{Patients and methods}

Our prospective study included 16 myopic patients, 10 women and six men, aged between 32 and 52 years, who presented with unilateral recalcitrant recurrent corneal erosion. Their myopia ranged between -2.0 and -7.0 dioptres and astigmatism ranged between -1.0 and -3.5 dioptres. All had recurrent corneal erosion unresponsive to our routine treatment, which included scraping off all the loose epithelium up to the limbus, patching with antibiotic ointment, and maintenance treatment by a lubricating ointment at bedtime. In 11 patients $(68.7 \%)$ the corneal erosion recurred once following the first attack which was treated by scraping and a patch; in five patients $(31.3 \%)$ the corneal erosion recurred twice.

Twelve patients $(75 \%)$ reported a previous episode of corneal trauma in the affected eye, and in four patients $(25 \%)$ the corneal erosion had occurred spontaneously.

All patients had signs of EBMD, including microcysts, intraepithelial debris, fingerprint patterns or map patterns, at least in one eye. The duration of symptoms of the epithelial basement membrane disease, such as pain upon waking, visual blur, and photophobia, ranged between 9 and 26 months with a mean of 18 months. The follow up time after excimer laser treatment ranged from 26 to 42 months with a mean of 31 months (Table 1).

Each patient underwent both subjective and cycloplegic refraction, achieving the best corrected visual acuity. However, when significant 


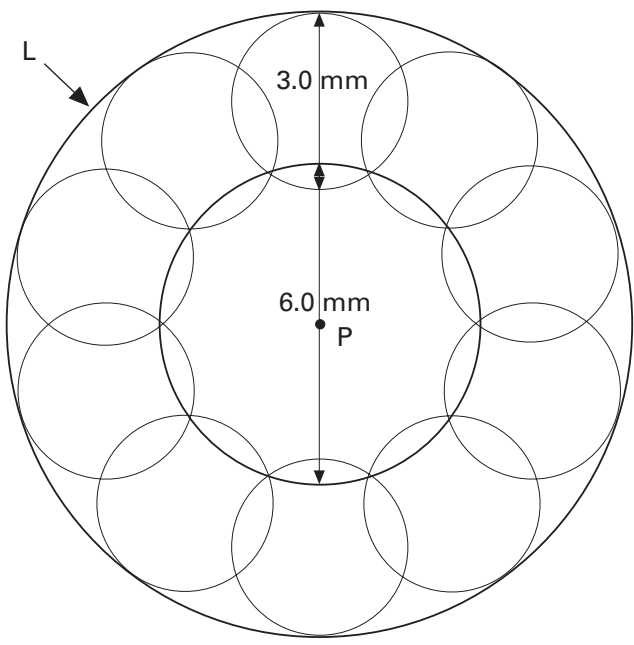

Figure 1 PRK-PTK treatment scheme illustrating the central $6 \mathrm{~mm}$ diameter zone of PRK, surrounded by confluent $3 \mathrm{~mm}$ diameter circular zones of PTK, reaching the corneal limbus $(L)$.

corneal surface irregularity was present, the cylinder and spherical error to be treated was calculated according to the patient's present spectacle data.

The method of combined PRK and PTK performed was as follows: the whole epithelium was scraped up to the limbal zone with a Beaver blade; PRK was subsequently performed with the Visx 20/20 excimer laser at a 6 $\mathrm{mm}$ diameter ablation zone centred on the pupil, for correction of the spherical component of the myopia. We attempted to correct both the myopia and astigmatism according to the preoperative refraction. When astigmatism was also present, it was corrected with a 4.8 $\mathrm{mm}$ slit width for cylinders up to -2.5 dioptres, and with a $5.0 \mathrm{~mm}$ slit width for cylinders between -2.5 and -3.5 dioptres. Subsequently, the laser computer program was changed to the PTK mode and the treatment zone diameter was programmed at $3.0 \mathrm{~mm}$ with a depth of $6 \mu \mathrm{m}$. Thereafter, the whole area of Bowman's layer peripheral to the PRK zone, was treated up to the limbus, by confluent $3.0 \mathrm{~mm}$ diameter circles of PTK at a depth of $6 \mu \mathrm{m}$ (Fig 1).

Following treatment, the eye was patched with chloramphenicol $(5 \%)$ ointment. On the following day, garamycin, Voltaren (diclofenac), and dexamethasone drops were applied together with chloramphenicol ointment, three times a day, until complete epithelialisation. Thereafter, dexamethasone drops were administered five times a day for 1 month, and then gradually tapered off within 5 months.

\section{Results}

The duration of re-epithelialisation ranged between 7 and 9 days with a mean of 8.5 days. All patients showed complete alleviation of their symptoms 1 month after treatment, with no recurrence of corneal erosion during their follow up. The uncorrected visual acuity following treatment ranged between $6 / 9$ and $6 / 12$. The postoperative best corrected visual acuity (BVA) did not change compared with the preoperative BVA in six eyes, improved by at least two Snellen lines in eight eyes, and was reduced by one Snellen line in two eyes (Table 1). It should be noted that in those eight patients in whom BVA improved after treatment, the loose epithelium and/or anterior basement membrane pathology were located centrally. Therefore, the preoperative subjective refraction was inaccurate, and PRK had to be performed according to the previous spectacle prescription. The final refraction following treatment ranged between +0.25 and -1.0 dioptres spherical equivalent (Table 1). Visual rehabilitation was gradual and relatively slow, as the post-treatment BVA reached its maximal level within a period of 5-6 months (mean 5.2 months). All patients underwent PRK in the other eye within a period of 4-6 months following treatment of the affected eye. A +1 diffuse faint subepithelial haze was still present at the end of the follow up period in those patients with a spherical equivalent higher than -4.12 dioptres (nine out of 16 eyes).

\section{Discussion}

There are several reports on the treatment of recalcitrant recurrent corneal erosion syndrome by excimer laser PTK. ${ }^{23-31}$ The reported rate of success, regarding alleviation of symptoms and prevention of recurrence of epithelial erosion, ranges between $74.4 \%$ and $100 \% .^{23-31}$

Table 1 Patient data

\begin{tabular}{|c|c|c|c|c|c|c|c|c|c|c|}
\hline \multirow[b]{2}{*}{ Patient No } & \multirow[b]{2}{*}{ Aetiology } & \multicolumn{4}{|l|}{ Preoperative } & \multicolumn{4}{|l|}{ Postoperative } & \multirow{2}{*}{$\begin{array}{l}\text { Follow up } \\
\text { (months) }\end{array}$} \\
\hline & & Refraction & $U V A$ & $B V A$ & $S E$ & Refraction & $U V A$ & $B V A$ & $S E$ & \\
\hline 1 & Trauma & $-1.75 /-1.25 \times 90^{\circ}$ & $6 / 20$ & $6 / 6(-)$ & -2.4 & $+0.50 /-0.5 \times 90^{\circ}$ & $6 / 9(+)$ & $6 / 6(-)$ & +0.25 & 34 \\
\hline 2 & Trauma & $-2.50 /-1.50 \times 135^{\circ}$ & $6 / 30$ & $6 / 9(-)$ & -3.25 & Plano/ $-0.5 \times 130^{\circ}$ & $6 / 9$ & $6 / 6$ & -0.25 & 42 \\
\hline 3 & Spontaeous & $-2.00 /-1.25 \times 75^{\circ}$ & $6 / 30$ & $6 / 6$ & -2.6 & Plano/ $-0.5 \times 70^{\circ}$ & $6 / 9$ & $6 / 6$ & -0.1 & 26 \\
\hline 4 & Trauma & $-3.50 /-1.25 \times 70^{\circ}$ & $6 / 60$ & $6 / 10$ & -4.1 & $-0.5 /-0.5 \times 80^{\circ}$ & $6 / 9(-)$ & $6 / 6(=)$ & -0.75 & 36 \\
\hline 5 & Trauma & -3.00 & $6 / 30$ & $6 / 7$ & -3.0 & -0.5 & $6 / 9(+)$ & $6 / 7$ & -0.5 & 38 \\
\hline 6 & Trauma & $-3.00 /-1.50 \times 45^{\circ}$ & $6 / 60$ & $6 / 6$ & -3.75 & $+0.50 /-1.0 \times 40^{\circ}$ & $6 / 9$ & $6 / 6$ & Plano & 26 \\
\hline 7 & Spontaneous & -3.25 & $6 / 30$ & $6 / 12$ & -3.25 & -0.5 & $6.9(+)$ & $6 / 6$ & -0.5 & 30 \\
\hline 8 & Trauma & $-3.75 /-1.5 \times 90^{\circ}$ & $6 / 60$ & $6 / 6$ & -4.5 & Plano $/-0.5 \times 90^{\circ}$ & $6 / 9$ & $6 / 6$ & -0.25 & 30 \\
\hline 9 & Trauma & $-3.50 /-1.75 \times 180^{\circ}$ & $6 / 60$ & $6 / 6$ & -4.4 & Plano/ $-0.75 \times 180^{\circ}$ & $6 / 9(-)$ & $6 / 6$ & -0.4 & 28 \\
\hline 10 & Trauma & $-4.00 /-2.50 \times 80^{\circ}$ & $6 / 120(-)$ & $6 / 10$ & -5.25 & Plano/ $-1.00 \times 70^{\circ}$ & $6 / 9(=)$ & $6 / 6(=)$ & -0.5 & 29 \\
\hline 11 & Spontaneous & $-4.00 /-1.75 \times 90^{\circ}$ & $6 / 120$ & $6 / 12$ & -4.9 & $-0.5 /-0.75 \times 90^{\circ}$ & $6 / 12(+)$ & $6 / 6(-)$ & -0.9 & 27 \\
\hline 12 & Trauma & $-4.75 /-3.00 \times 120^{\circ}$ & $6 / 120$ & $6 / 10$ & -6.25 & $+0.5 /-1.25 \times 110^{\circ}$ & $6 / 9(-)$ & $6 / 6(=)$ & -0.1 & 27 \\
\hline 13 & Trauma & $-5.50 /-3.50 \times 90^{\circ}$ & $\mathrm{FC}$ & $6 / 12$ & -7.25 & Plano/ $-1.50 \times 90^{\circ}$ & $6 / 12(+)$ & $6 / 9(-)$ & -0.75 & 30 \\
\hline 14 & Spontaneous & -6.0 & $6 / 120$ & $6 / 12$ & -6.0 & -0.5 & $6 / 9(+)$ & $6 / 6$ & -0.5 & 32 \\
\hline 15 & Trauma & -7.0 & FC & $6 / 6$ & -7.0 & Plano/ $-0.50 \times 90^{\circ}$ & $6 / 9(=)$ & $6 / 9$ & -0.25 & 31 \\
\hline 16 & Trauma & $-7.0 /-2.00 \times 115^{\circ}$ & FC & $6 / 6$ & -8.0 & $-0.5 /-1.00 \times 110^{\circ}$ & $6 / 12$ & $6 / 9$ & -1.0 & 31 \\
\hline
\end{tabular}

$\mathrm{UVA}=$ uncorrected visual acuity; BVA = best corrected visual acuity; SE = spherical equivalent; $(-)=$ one letter less; $(=)=$ two letters less; $(+)=$ one letter more 
Dausch et al $^{23}$ reported a success rate of $74.4 \%$ in 74 eyes treated by PTK. O'Brart et al ${ }^{27}$ reported that four out of 17 eyes $(23.5 \%)$ experienced recurrent episodes 3-6 months after PTK and two have subsequently been retreated, one of whom has been symptom free for 12 months following retreatment. Postoperative BVA was unaltered in nine eyes and improved by at least one Snellen line in eight eyes. Both Forster et $a l^{31}$ and Algawi et $a l^{24}$ reported that none of their treated patients had experienced recurrence of corneal erosion. However, Algawi et al ${ }^{4}$ reported that two of 14 patients still complained of transient, recurrent foreign body sensation following PTK, although none of their patients developed recurrence of the erosion.

Öhman et al ${ }^{26}$ reported that 20 of 76 treated eyes $(26.3 \%)$ had recurrences following PTK. Thirty five of their patients had no symptoms after treatment and 21 patients had minor symptoms. In all the above mentioned studies, ${ }^{23-31}$ the method of PTK included focal ablation restricted to the affected zone of corneal epithelium, at a maximal depth of 40 $\mu \mathrm{m}$ whenever there was no actual erosion. Alternatively, when a true erosion was present together with loose epithelial margins, the corneal area not covered with epithelium was treated superficially at an ablation depth between 1 and $5 \mu \mathrm{m}$, in order to interfere as little as possible with Bowman's layer. ${ }^{23}$ Subsequently, the loose epithelium beyond the margins of the erosion was treated directly within an area of one laser spot size of $1.5 \mathrm{~mm}$, at a depth of 30-40 $\mu \mathrm{m}^{23}$ Algawi et $a l^{24}$ and O'Brart et $a l^{27}$ reported that they mechanically removed the locally loose epithelium, and subsequently a 20-30 pulse ablation was applied to Bowman's layer, achieving an ablation depth of 5-7 $\mu \mathrm{m}$. Recently, Kaplan-Messas et al ${ }^{32}$ reported, for the first time, a study comparing the results of the above described focal mode of PTK treatment with the results of a diffuse mode of PTK, whereby they shot 54 pulses spread over the entire Bowman's layer following total epithelial debridement, in nine overlapping $6 \mathrm{~mm}$ diameter spots with a mean ablation depth of $2 \mu \mathrm{m}$. Patients were monitored for refractive and topographic changes. Two eyes with focal PTK, but no eye with diffuse PTK had recurrent ulcers after a mean follow up of 8.0 (SD 2.49) and 9.03 (2.62) months, respectively. A final hyperopic shift was found, but it was not significantly different between the two groups. The vectorial change of astigmatism was significantly lower in the focal PTK group, but surface regulatory index changes were not significantly different between the two groups. ${ }^{32}$

Interestingly, the diffuse PTK method utilised by the latter authors ${ }^{32}$ is quite similar to our method of combined PRK and PTK, which actually includes pancorneal ablation. However, our method is different in the sense that the central $6 \mathrm{~mm}$ ablation depth is much deeper as PRK, and not PTK, is performed in this zone. The stromal ablation depth in the central $6 \mathrm{~mm}$ zone of PRK depends on the degree of myopia.
Lind et $a l^{33}$ in a recent presentation on excimer laser treatment for RCE, reported that the overall refractive change in 43 PTK treated patients was a hyperopic shift of 0.69 dioptres. These authors ${ }^{33}$ did not mention whether they utilised the diffuse or focal mode of PTK. Kaplan-Messas et $a l^{32}$ found a hyperopic shift of 0.87 (0.81) dioptres in the diffuse treatment group and $0.38(0.74)$ dioptres in the focal treatment group. However, there was no statistically significant difference between the two groups. In our group of patients, there was only one eye out of $16(6.2 \%)$ which had a post-treatment spherical equivalent of +0.25 dioptres; the remainder ( 15 eyes) had a spherical equivalent ranging between plano and -1.0 dioptre. Fourteen out of 16 eyes $(87.5 \%)$ had a final myopic spherical equivalent less or equal to -1.0 dioptre. This small myopic shift compared with the hyperopic shift found in previous studies ${ }^{32}$ may be related to the peripheral confluent PTK treatment, surrounding the central zone of PRK or to the inaccurate pre-PRK refraction performed in those patients with central RCE. As PRK was not performed in these two studies ${ }^{32}$ it is impossible to compare their refraction results and our refraction results following treatment. Additionally, the number of patients included in our study is relatively small compared with the latter two studies. ${ }^{32} 33$

With regard to our excimer laser ablation technique, it should be noted that Gibralter and Trokel $^{34}$ reported their excimer ablation technique, developed in order to create a regular optical surface. They customised an ablation programme using circular PTK elements of varying diameters, to flatten identified high areas on corneal topography, and a standard myopic ablation to achieve central flattening and elimination of residual myopia. These two techniques are quite similar, although they were utilised for the different corneal disorders.

Pertaining to the high rate of success of our above described method of treatment, we postulate that the diffuse pancorneal ablation induces a better adhesion capacity of the whole basal epithelium to the stromal bed. It has been shown that following excimer laser ablation, a normal structured basement membrane with its anchoring filaments and adhesion proteins finally develops. ${ }^{35}$ We believe that recalcitrant RCE is a diffuse disease of the corneal epithelium and its basement membrane, although it quite often presents as a local abnormality. Therefore, it should be treated extensively either by the diffuse PTK method described by Kaplan-Messas et $a l^{32}$ or by the combined PRK and PTK method which was performed in our above presented myopic patients. Unfortunately, we did not have a control group of RCE patients treated by focal PTK, with whom we could compare our results.

It is important to note that Fountain et al ${ }^{35}$ have found that following excimer laser keratectomy, the anchoring fibrils, hemidesmosomes, and the basal lamina do not completely normalise even after 15 months. ${ }^{35}$ Therefore, we are of the opinion that it is imperative to 
follow these patients for at least 15 months after diffuse PTK, before drawing any conclusions regarding the effect of this treatment on the recurrence of corneal epithelial erosion.

Presented at the ESCRS Meeting, Sweden 1996 and ARVO Meeting, USA, 1997

1 Waring GO, Rodrigues MM, Laibson PR. Corneal dystrophies. 1. Dystrophies of the epithelium. Bowman's layer phies. 1. Dystrophies of the epithelium. Bowm
and stroma. Surv Ophthalmol 1978;23:71-122.

2 Dohlman CN. Healing problems in the corneal epithelium. fpn F Ophthalmol 1981;25:131-4.

3 Bron AJ, Brown N. Recurrent erosion of the cornea. $\mathrm{Br} F$ Ophthalmol 1976;60:84-91.

4 Bron AJ, Brown NA. Some superficial corneal disorders. Trans Ophthalmol Soc UK 1971;91:13-30.

5 Williams R, Buckley R. Pathogenesis and treatment of recurrent corneal erosion. Br F Ophthalmol 1985;69:435-7.

6 Khodadoust AA, Silverstein AM, Kenyon KK, Dowling JE. Adhesion of regenerating corneal epithelium: the role of basement membrane. Am f Ophthalmol 1968;65:339-48.

7 Trapathi RC, Bron AJ. Ultrastructural study of nontraumatic recurrent corneal erosion. Brf Ophthalmol 1972; 56:73-85.

8 Rodrigues MM, Fine BS, Laibson PR, Zimmerman LE. Disorders of the corneal epithelium: a clinicopathologic study of dot, geographic and fingerprint patterns. Arch Study of dot, geographic and

9 Coghthalmol 1974;92:475-82. cogan DG, Kuwabara T, Donaldson DD, Collins E. Micro-
cystic dystrophy of the cornea: a partial explanation for its cystic dystrophy of the cornea: a partial explan
pathogenesis. Arch Ophthalmol 1974;92:470-4.

pathogenesis. Arch Ophthalmol 1974;92:470-4.
10 Fogle JA, Kenyon KR, Stark WJ, Green WR. Defective epithelial adhesions in anterior corneal dystrophies. Am $\mathcal{F}$ Ophthalmol 1975;79:925-40.

11 Brodrick JD. Anterior membrane dystrophy following cataract extraction. Brf Ophthalmol 1979;63:331-5.

12 Goldman JN, Dohlman CH, Kravitt BA. The basement membrane of the human cornea in recurrent erosion syndrome. Trans Am Acad Ophthalmol Otolaryngol 1969;73 471-81.

13 Frangieh GT, Kenyon KR, Wagoner MD, Hanninen L, John $\mathrm{T}$, Steinert RF, et al. Epithelial abnormalities and sterile ulceration of epikeratoplasty grafts. Ophthalmology 1988; 95:213-27.

14 Hykin PG, Foss AE, Paversio C, Dart JKG. The natural history and management of recurrent corneal erosion: tory and management of recurrent corneal

15 Mindel J. Therapeutic uses of contact lenses. Surv Ophthalmol 1989;33:381-94.

16 McLean EN, McRae SM, Rich LF. Recurrent erosion: treatment by anterior stromal puncture. Ophthalmology 1986;93:784-7.

17 McRae SM, McLean EN, Rich LF. Anterior stromal puncture for recurrent corneal erosion: further experience and new instrumentation. Ophthalmic Surg 1990;21:318-26.
18 Buxton JN, Constad WH. Superficial epithelial keratectomy in the treatment of epithelial basement membrane dystrophy. Ann Ophthalmol 1987;19:92-6.

19 Buxton JN, Constad WH. Superficial epithelial keratectomy. Cornea 1987;6:292-7.

20 Rubinfeld RS, McRae SM, Laibson PR. Successful treatment of recurrent corneal erosion with Nd:YAG anterior stromal puncture. Am f Ophthalmol 1991;111:252-3.

21 Geggel HS. Successful treatment of recurrent corneal erosion with Nd:YAG anterior stromal puncture. $A m \mathcal{F}$ Ophthalmol 1990;110:404-7.

22 Wood TO, McLaughlin BJ, Boykins LG. Electron microscopy of corneal surface microdiathermy. Curr Eye Res $1985 ; 4: 885-8$

23 Dausch D, Landesz M, Klein R, Schröder E. Phototherapeutic keratectomy in recurrent corneal epithelial erosion. Refract Corneal Surg 1993;9:419-24.

24 Algawi K, Goggin M, O'Keefe M. $193 \mathrm{~mm}$ excimer laser phototherapeutic keratectomy for recurrent corneal erosions. Eur J Implant Refract Surg 1995;7:11-3.

25 Tuunanen TW, Tervo TM. Excimer laser phototherapeutic keratectomy for corneal diseases; a follow-up study. CLAO f 1995;21:67-72.

26 Ôhman L, Fagerholm P, Tengroth B. Treatment of recurrent corneal erosions with the excimer laser. Acta Ophthalmol Copenh 1994;72:461-3.

27 O'Brart DP, Muir MG, Marshall J. Phototherapeutic keratectomy for recurrent corneal erosions. Eye 1994;8: $378-83$.

28 Gyldenkerne GJ, Ehlers N. Excimer laser therapy of recurrent corneal erosions. Ugeskr-Laeger 1994;156:5282-4.

29 Poirier L, Coulon P, Williamson W, Mortemousque B, Verin P. Results of therapeutic keratectomy using the excimer P. Results of therapeutic keratectomy using the excimer
laser. A propos of 12 cases. (French) 7 Fr Ophtalmol 1994; 17:262-70.

30 Thon ME, Van-der-Karr MA, Noblitt RL, Boleyn KL. Excimer laser phototherapeutic keratectomy for treatment of recurrent corneal erosion. F Cataract Refract Surg 1994; 20:179-81.

31 Förster W, Grewe S, Atzler V, Lunecke C, Busse H. Phototherapeutic keratectomy in corneal diseases. Refract Corneal Surg 1993;9(suppl):85-90.

32 Kaplan-Messas A, Assouline M, Saragoussi JJ, David T, Abenhaim A, Poulquen Y. Diffuse versus focal photoablation for recurrent epithelial erosion. ARVO Abstract No 2646. Invest Ophthalmol Vis Sci 1996;37:S574.

33 Lind DM, Cavanaugh TB, Durvie DS, Mack RL, Cutarelli PE, Timerlake GT, et al. Phototherapeutic keratectomy for recurrent erosion syndrome. ARVO Abstract No 2635. Invest Ophthalmol Vis Sci 1996;37:S572.

34 Gibralter R, Trokel S. Correction of irregular astigmatism with the excimer laser. Ophthalmology 1994;101:1310-5.

35 Fountain TR, de la Cruz Z, Green WR, Stark WJ, Azar DT. Reassembly of corneal epithelial adhesion structures after excimer laser keratectomy in humans. Arch Ophthalmol 1994;112:967-2. 